Journal of Economics and Behavioral Studies

Vol. 4, No. 5, pp. 239-244, May 2012 (ISSN: 2220-6140)

\title{
Stock Market Returns and Weather Anomaly: Evidence from an Emerging Economy
}

\author{
*Hammad Hassan Mirza1', Muhammad Jam e Kausar Ali Asghar², Naveed Mushtaq1 \\ ${ }^{1}$ University of Sargodha, Sargodha, Pakistan \\ ${ }^{2}$ COMSATS Institute of Information Technology, Islamabad, Pakistan \\ *hammadhassan@uos.edu.pk
}

\begin{abstract}
Financial economists believe that the arbitrage forces in the market are the main reason of market efficiency and these forces are the fundamental concept of efficient market hypothesis (EMH). During last few years, various theoretical and empirical evidences have been presented to support the work of financial modeling for the markets with less than rational investors whose trading strategies are based on psychological factors like mood and emotions. Weather condition is among the substantial factors affecting investors' mood and emotions. Present study investigates the impact of temperature on stock market returns in emerging economy of Pakistan. Using the daily temperature records and stock market indices of Karachi and Islamabad, the study has employed auto regressive (AR) - generalized autoregressive conditional heteroscedasticity (GARCH) model from 2006 to 2010. Based on AR (1)-GARCH $(1,1)$ estimation the study has found that weather temperatures of both Karachi and Islamabad are negatively related with Karachi Stock Exchange (KSE) and Islamabad Stock Exchange (ISE) index returns, respectively.
\end{abstract}

Keywords: Behavioral finance; Market anomaly; Weather effect; AR-GARCH model, Temperature effect

\section{Introduction}

During the last decade behavioral finance has emerged as a new approach to interpret market anomalies in developed and emerging economies. It has gained importance as an alternative and intuitive paradigm to understand the relationship between human psychology and market performance. The traditional economic approach of financial market analysis is heavily based on the assumption of investor's rationality which means that agents update their beliefs correctly (Bayes' Law) ${ }^{1}$ and make choices that are normatively acceptable (Subjective Expected Utility-SEU) ${ }^{2}$. Although traditional approach is simple and appealing but after several years of research it has now become evident that this framework is not fully capable of interpreting the relationship between aggregate stock market performance and individual trading behavior due to the fact investors are not expected to behave in a rational manner all the times. Behavioral finance has emerged in response to the shortcomings faced by traditional approach. It analyzes the impact of relaxation of any or both of rationality principles (i.e. Bayes law and SEU) on peoples' investment behavior. Although the fundamental of behavioral finance i.e. influence of investor's irrationality on market performance, has been challenged by the principle of arbitrage which states that even if some investors in the market are not fully rational but in the long run the rational investor will prevent them from influencing the stock market. The

${ }^{1}$ Bayes' Law is based on a mathematical equation which calculates the probability that " $A$ " is true or will be true provided the given circumstances like " $\mathrm{B}$ ". The Bayes' equation is : $P(A \mid B)=P(B \mid A) * P(A) / P(B)$

${ }^{2}$ Savage in 1954 promoted the SEU method in decision theory. He proved that if investor is rational and believe that an uncertain event has possible outcomes $\{x i\}$ each with a utility of $u\{x i\}$ then his choices would be arising from a function in which he believes that each outcome has a subjective probability and utility of outcome is the subjective expected value of utility. The reason of different decisions by different people is because of difference in their utility function about the probability of different outcomes. 
debate on the issue of rationality of investor and its impact of stock prices has generated a cosmic literature where a series of theoretical papers have shown that in the market where both rational and irrational investors interact, irrational investors have a substantial and long run influence on stock prices (Barberis and Thaler, 2003).

Behavioral finance studies the influence of investor's psychology on market performance and helps in explaining inefficiencies of market due to human behavior. The idea of relationship between human psychology and stock market was introduced by Selden (1912) in his famous book "Psychology of Stock Market", where he tried to establish that stock price movement is significantly dependent upon the mental attitude of investor himself. It is now, well established that people decision making is affected by their mood, feelings and emotions (Schwartz, 1990). The classical economics theory of investor's rationality supposes that investor behaves in a logical manner he can calculate possibilities while taking economic decisions. Numerous psychological evidences suggest that human judgments are affected by mood and emotions (Schwartz, 1990; Loewenstein et al., 2001). Frijda (1988) argued that peoples' ability to process information is influenced by mood. In reality, weather condition is among the major factors which influence human mood and emotions. Schwartz and Clore (1983) have argued that people feel life satisfaction more on sunny days than on cloudy/rainy days. Similarly, Cao and Wei (2005) suggested that low temperature causes aggression and high temperature causes both aggression and hysteria. Present study is an attempt to capture the effect of temperature and stock market returns in two cities of Pakistan ${ }^{3}$ i.e. Karachi and Islamabad. Rest of the paper is organized as follows: section 2 provides the relevant review of literature, section 3 discussed the research methodology and models. Results are discussed in section 4 and section 5 gives the conclusion.

\section{Literature Review}

It is commonly argued in psychological literature that emotions and feelings of people have impact on their decisions (Schwartz, 1990). For instance, Schwartz and Clore (1983) established that people rate their life satisfaction much higher on sunny days as compared to rainy or cloudy day. Regarding temperature, Cao and Wei (2005) have argued that low temperature creates aggression while high temperature tends to cause aggression and hysteria as well. The impact of temperature on stock returns has been observed by number of researchers both in developed and emerging economies. Saunders (1993) has analyzed the impact of cloudy days on stock returns using the data for the period 1927 to 1989 of New York. He found that in sunny days investors' mood is normally optimistic and upbeat, therefore, stock markets observe an increasing trend in sunny days. On the other side, during cloudy days investors behave pessimistically which ultimately depresses the stock returns. Hirshleifer and Shumaway (2003) confirmed the results of Saunders (1993) using 26 international stock indices. They further analyzed the impact of rainfall on stock return but found no significant relationship between rain and stock returns. Cao and Wei (2002) investigated the impact of temperature on stock returns and found that on average temperature has a negative relationship with stock returns that is; low temperatures are associated with high returns and vice versa. Tufan and Hamarat (2004) have analyzed the relationship between cloudy days and index returns of Istanbul Stock Exchange (ISE-100 index) from October 1986 to July 2002. They found that cloudy days do not cause any change in ISE 100 index. Keef and Roush (2005) have examined the impact of New York Weather on Dow Jones Industrial Average index and Standard and poor's 500 indexes from the period starting from 1984 to 2002. They found

\footnotetext{
${ }^{3}$ Pakistan is essentially arid with exception of Himalayas and sub mountainous tract where rainfall varies from 760 to $1270 \mathrm{~mm}$. The country is divided into four temperature regions. First, the hot summer and mild winter, second, warm summer and mild winter, third, warm summer and cool winter and fourth, mild summer and cold winter. In major parts of Pakistan weather remains dry with extreme high temperature, up to $45^{\circ} \mathrm{C}$, in summer and low temperature, up to $0^{\circ} \mathrm{C}$ during winter
} 
that level of wind as a weak determinant of stock returns; however, de-seasonalised temperature had a positive impact on stock returns on cool days but not on warm days. More recently, Sriboonchitta et al. (2011) have analyzed the relationship between temperature and stock returns in Thailand for the period of 1996 to 2010. By applying Autoregressive (AR)-Generalized Autoregressive Conditional Heteroscedasticity (GARCH), they found a negative relationship between temperature and stock market returns for Thailand. Base on existing literature the present study attempts to capture the impact of temperature on stock index returns in Islamabad and Karachi using AR-GARCH model.

\section{Methodology}

The present study has used daily weather (average temperature) and stock return data from Islamabad and Karachi during the period of 5 years starting from 2006 to 2010. The impact of Islamabad weather has been investigated on Islamabad Stock Exchange 10 index and of Karachi weather on Karachi Stock Exchange 100 index using GARCH model. The average daily temperature $\left(T E M P_{t}\right)$ represents the average of 24 hours temperature readings and daily index return $\left(R T R N_{t}\right)$ have been calculated as natural logarithmic price relatives given in equation 1 below.

$$
R T R N_{t}=\ln \left(\frac{P_{t}}{P_{t-1}}\right)
$$

Where $R T R N_{t}$ is the return and $\mathrm{P}_{\mathrm{t}}$ is the daily price at time t. In order to calculate the impact of daily temperature on daily stock return the present study has employed AR (p)-GARCH (p, q) model. The term AR (p) refers to autoregressive model of order $\mathrm{p}$ which is defined in equation 2 below:

$$
X_{t}=c+\sum_{i=1}^{p} \varphi_{i} X_{t-i}+\varepsilon_{t}
$$

Where $\varphi_{1}, \ldots \ldots . \varphi_{\mathrm{p}}$ are the parameters of the model, c represents the constant and $\varepsilon_{\mathrm{t}}$ is white noise. If $|\varphi| \geq 1$, then the AR(1) process will be considered as non stationary. A simple GARCH $(1,1)$ model specification includes conditional mean and conditional variance equations.

$$
\begin{aligned}
& Y_{t}=X_{t}^{\prime} \theta+\epsilon_{t} \\
& \sigma_{t}^{2}=\omega+\propto \epsilon_{t-1}^{2}+\beta \sigma_{t-1}^{2}
\end{aligned}
$$

Equation 3 is the mean equation written as the function of exogenous variables and error term. Equation 4 represents the conditional variance $\sigma 2$ which is the one period ahead forecast variance based on first order lagged information. In equation $4, \omega$ represents the constant term and the ARCH term is represented by $\epsilon^{2}(t-1)$, which is the information of volatility from previous period measured as the first order lagged squared residual from equation 3. The GARCH term is included as $\sigma^{2}(\mathrm{t}-1)$, which is the last period forecasted variance. ARCH model usually employed three assumptions i.e. normal distribution, t-distribution and Generalized Error Distribution (GED) and estimated by the method of maximum likelihood. In case the error is assumed to be normally (Gaussian) distributed than the contribution to the log likelihood for t observation is as below:

$$
l_{t}=-\frac{1}{2} \log (2 \pi)-\frac{1}{2} \log \sigma_{t}^{2}-\frac{1}{2}\left(y_{t}-X^{\prime} \theta\right)^{2} / \sigma_{t}^{2}
$$

On the other side, if the error term follows a student $t$ distribution, then the log likelihood would be as follows:

$$
l_{t}=-\frac{1}{2} \log \left[\frac{\left\{\pi(v-2) \Gamma(v \div 2)^{2}\right\}}{\Gamma\{(v+1) \div 2\}^{2}}\right]-\frac{1}{2} \log \sigma_{t}^{2}-\frac{v+1}{2} \log \left[1+\frac{\left(y_{t}-X_{t}^{\prime} \theta\right)^{2}}{\sigma_{t}^{2}(v-2)}\right]
$$

The present study uses GARCH $(1,1)$ model with two distribution assumption given above in equation 5 and 6. The mean equation, given below, includes the autoregressive term of order one and temperature variable. The present study has applied AR(1)-GARCH(1,1) model due to its strength to account for temporal dependence in variance and excess kurtosis. The conditional mean (eq-7) and conditional variance equations (eq-8) of AR-GARCH model are as follows:

$$
\begin{aligned}
& R_{t}=c_{0}+c_{1} R_{t-1}+c_{2} T E M P_{t}+\varepsilon_{t} \\
& \sigma_{t}^{2}=\omega+\alpha \epsilon_{t-1}^{2}+\beta \sigma_{t-1}^{2}+e
\end{aligned}
$$


In order to analyze the impact of temperature on stock index returns, the average temperature of Islamabad has been used against ISE stock index returns. The same model, then, again has been used to analyze the impact of average temperature of Karachi on KSE stock index returns for the period 2006 to 2010. The option of heteroscedasticity consistent covariance has been used to compute quasi-maximum likelihood (QML) covariance, moreover, Bollerslev and Wooldridge (1992) method of standard error computation has been applied also. The estimated results have been presented in next section.

\section{Results and Discussion}

Table 1 below represents descriptive statistics of main variables of the study, i.e. market returns and temperature of Islamabad and Karachi. The mean temperature of Karachi is higher than Islamabad but Karachi's highest temperature is less than Islamabad higher temperature. Furthermore, Islamabad's weather becomes colder in winter as compared to Karachi's weather. Karachi's atmosphere remains more stable during all seasons as compared to Islamabad. Therefore, the present study expects greater tendency of weather to affect investor's behavior in Islamabad than Karachi. The ISE and KSE stock indices show slightly excess kurtosis that is leptokurtic, which is natural behavior of index returns around the world. Financial research has shown that returns are characterized by leptokurtosis, skewness and volatility clustering (Sriboonchitta et al. 2011). The Jarque Bera test of normality assumption has been rejected at the level 1\% for both returns and temperature. All returns are stationary while temperature data is characterized by seasonality factor. The summary statistics are presented in table 1 below.

Table 1: Summary statistics

\begin{tabular}{lllll}
\hline & Islamabad & & Karachi \\
\hline Mean & Returns (ISE) & Temperature & Returns (KSE) & Temperature \\
Median & 0.0002 & 22.7559 & 0.0000 & 27.2233 \\
Maximum & 0.0007 & 25.0000 & 0.0009 & 28.8000 \\
Minimum & 0.0411 & 34.1000 & 0.0325 & 32.4000 \\
Std. Dev. & -0.0503 & 7.8000 & -0.0398 & 16.7000 \\
Skewness & 0.0161 & 7.3938 & 0.0128 & 4.1205 \\
Kurtosis & -0.3435 & -0.3921 & -0.5202 & -0.8652 \\
Jarque-Bera & 4.9399 & 1.7919 & 4.8992 & 2.5200 \\
Probability & 58.622 & 89.712 & 76.751 & 130.881 \\
Observations & 0.000 & 0.000 & 0.000 & 0.000 \\
ADF (level) & 1038 & 1038 & 974 & 974 \\
ADF (1 ${ }^{\text {st }}$ diff) & -29.844 & -- & -28.094 & -- \\
Critical Value 1\% & -17.2835 & -- & -17.557 & -- \\
Critical Value 5\% & -3.43644 & -- & -3.4364 & -- \\
Critical Value 10\% & -2.8643 & -- & -2.8643 & -- \\
\hline
\end{tabular}

Tables 2 and 3 present the estimated results from AR-GARCH model for Islamabad and Karachi respectively. Both tables are classified in to two columns representing estimated results with normal and student's $t$ distribution (the results from general error distribution GED are not presented here). The coefficient of temperature is significantly negative at the level $10 \%$ and $5 \%$ for normal and student's $t$ distribution respectively for Islamabad. The sum of ARCH and GARCH terms are closer to one which means that volatility shocks are quite persistent. Moreover the GARCH term is significant and higher than ARCH term which shows that volatility shocks conditional variance will exhibit long term persistence of volatility. The coefficient of temperature is low but significant which means that Islamabad stock index has a negative relationship with temperature. These results have been reconfirmed in table 3 for Karachi. The temperature coefficient of 
Karachi is also low and negative but significant only under normal distribution assumption. These results are in line with the results reported by Cao and Wei (2005) and Sriboochitta (2011). It is therefore; sufficed to conclude that weather temperature has a negative influence on stock returns in Pakistan. The estimated results of both Islamabad and Karachi have been presented below:

Table 2: AR(1)-GARCH(1,1) Results under different distributions for Islamabad

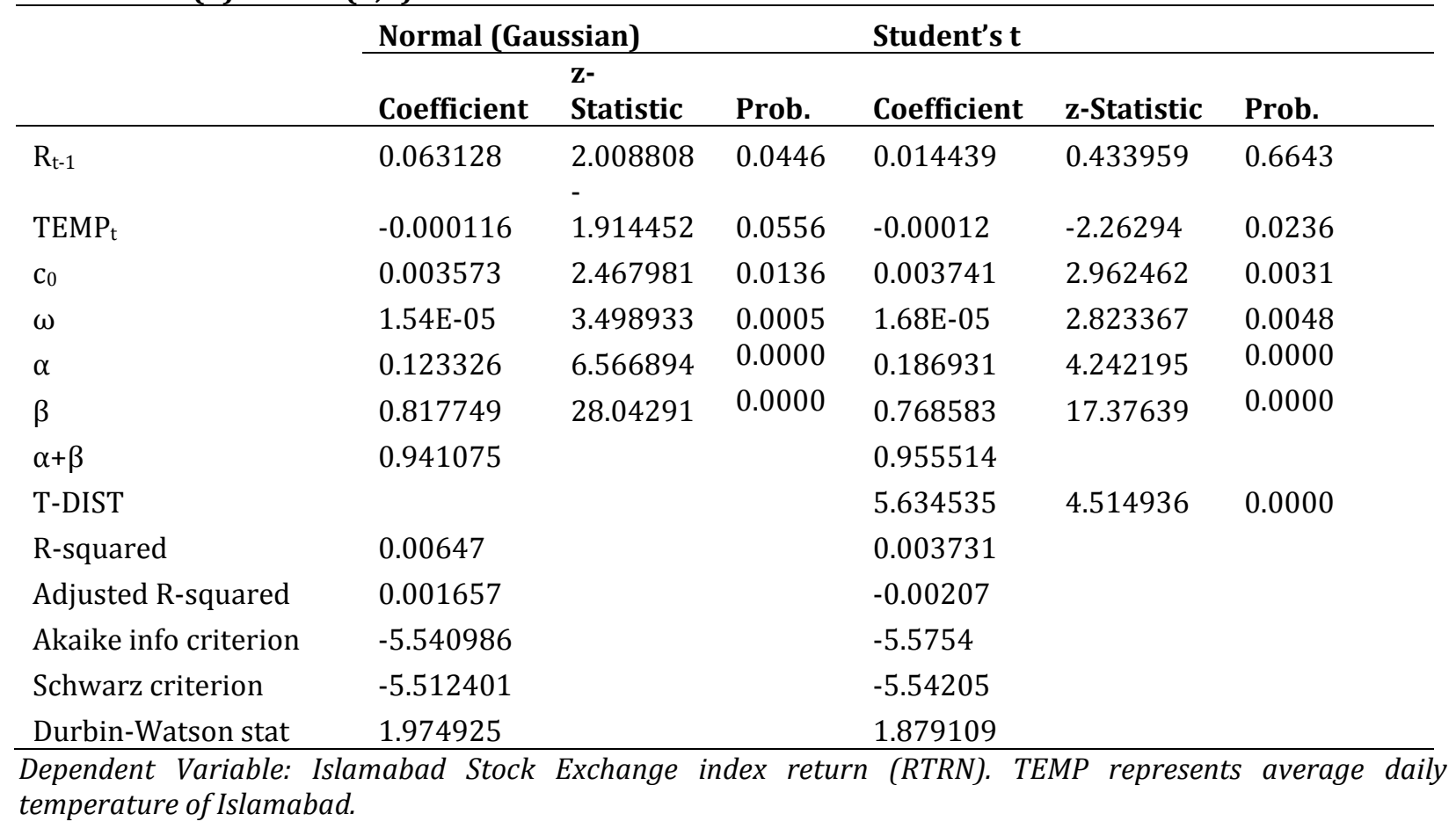

Table 3: AR (1)-GARCH $(1,1)$ Results under different distributions for Karachi

\begin{tabular}{|c|c|c|c|c|c|c|}
\hline & \multicolumn{3}{|c|}{ Normal (Gaussian) } & \multicolumn{3}{|l|}{ Student's t } \\
\hline & Coefficient & z-Statistic & Prob. & Coefficient & z-Statistic & Prob. \\
\hline $\mathrm{R}_{\mathrm{t}-1}$ & 0.122942 & 3.470482 & 0.0005 & 0.098835 & 2.936214 & 0.0033 \\
\hline $\mathrm{TEMP}_{\mathrm{t}}$ & $-8.36 \mathrm{E}-05$ & -2.389752 & 0.0128 & $-8.05 \mathrm{E}-05$ & -1.02929 & 0.3033 \\
\hline $\mathrm{c}_{0}$ & 0.00283 & 1.376204 & 0.1688 & 0.0032 & 1.510413 & 0.1309 \\
\hline$\omega$ & $1.16 \mathrm{E}-05$ & 2.656652 & 0.0079 & $1.10 \mathrm{E}-05$ & 2.932297 & 0.0034 \\
\hline$\alpha$ & 0.127025 & 4.419816 & 0.0000 & 0.184608 & 4.048342 & 0.0001 \\
\hline$\beta$ & 0.802631 & 17.31927 & 0.0000 & 0.767612 & 17.12696 & 0.0000 \\
\hline$\alpha+\beta$ & 0.929656 & & & 0.952220 & & \\
\hline T-DIST & & & & 5.95297 & 4.136724 & 0.0000 \\
\hline R-squared & 0.012153 & & & 0.007318 & & \\
\hline Adjusted R-squared & 0.00705 & & & 0.001158 & & \\
\hline Akaike info criterion & -5.985597 & & & -6.01678 & & \\
\hline Schwarz criterion & -5.955527 & & & -5.98169 & & \\
\hline Durbin-Watson stat & 2.032031 & & & 1.975731 & & \\
\hline
\end{tabular}




\section{Conclusion}

The traditional economic approach of stock market analysis is heavily based on the assumption of investors' rationality which says that investor is capable of taking correct decision all the times. However, it is now empirically evident that investors' decisions are influence by number of different factors which are associated with nature like temperature, sunshine, cloudy or rainy weather etc. The studies on stock market anomalies due to weather conditions like temperature, relies on psychological explanation of impact of temperature on people's behavior. Psychological literature suggests that low temperature lead to aggression while high temperature can cause apathy as well. The present has attempted to investigate the impact lack of investors' interest and aggression due to high temperature on stock index return in Islamabad and Karachi for the period of 2006 to 2010. For this purpose AR-GARCH model is applied under two distributional assumption i.e. normal and student's-t and found a significantly negative impact of weather temperature on stock index returns of both ISE and KSE. Although the weather effect on stock returns is unobservable in daily return patterns but estimated results based on time series analysis suggest that weather does have impact on stock returns therefore, investors and speculators should consider climate changes while making investment decisions, especially in the long run.

\section{References}

Barberis, N. C. \& Thaler, R. H. (2003). A Survey of Behavioral Finance. In: George M. Constantinides, Milton Harris, and Ren_e M. Stulz, eds. Handbook of the Economics of Finance: Volume 1B, Financial Markets and Asset Pricing. Elsevier North Holland, 18, 1053-1128.

Bollerslev, T. \& Wooldridge, J. M. (1992). Quasi-maximum likelihood estimation and inference in dynamic models with time varying covariances. Econometric Reviews, 11, 143-72.

Cao, M. \& Wei, J. (2002). Stock market returns: a temperature anomaly. Working Paper, Schulich School of Business, York University, Canada.

Cao, M. \& Wei, J. (2005). Stock market returns: a note on temperature anomaly. J Banking Finance, 29, 155973.

Frijda, N. (1988). The laws of emotion. Cognition and Emotion, 1, 235-258.

Hirshleifer, D. \& Shumaway, T. (2003). Good Day Sunshine: Stock Returns and the Weather. Journal of Finance, $58,1009-1032$.

Keef, S. P. \& Roush, M. L. (2005). Stock prices and Wall Street weather: revisited. Eurasian Review of Economics and Finance, 1, 31- 44.

Loewenstein, G. F., Elke, U. W., Christopher, K. H. \& Welch, N. (2001). Risk as feelings. Psychological Bulletin, $127,267-286$.

Saunders, E. M. J. (1993). Stock prices and Wall Street weather. American Economic Review, 83, 1337-1345.

Schwartz, N. (1990). Feelings as information: informational and motivational functions of affective states. In Higgins and Sorrentino, Handbook of Motivation and Cognition New- York, Guildford Press. 2, 527561..

Schwarz, N. \& Clore, G. L. (1983). Mood, misattribution and judgments of well-being: indirect functions of affective states. Journal of Personality and Social Psychology, 45, 513-523.

Selden, G. C. (1912). Psychology of the Stock Market: Human Impulses Lead To Speculative Disasters. New York: Ticker Publishing.

Sriboonchitta, S., Chitip, P., Sriwichailamphan, T. \& Chaiboonsri, C. (2011). Stock market returns and the temperature effect. Thailand International Research Journal of Management and Business Studies, 1(1), 012-016.

Tufan, E. \& Hamarat, B. (2004). Do Cloudy Days Affect Stock Exchange Returns: Evidence from Istanbul Stock Exchange? Journal of Naval Science and Engineering 2(1), 117-126. 